\title{
63. Expressing Conditions using Level 88
}

A neat way of expressing conditions is to define them in the Data Division. For example, suppose that a data item called FINISHED-INDICATOR will be set to ' $\mathrm{Y}$ ' when the user has finished inputting data - it is possible to give a name to the condition of having finished by using Level 88 under the data definition for the item:

01 FINISHED-INDICATOR PIC $X$. 88 FINISHED VALUE ' $Y$ ','y'

In the Procedure Division - the statement -

PERFORM PROCESS-DATA-RECORD UNTIL FINISHED

may then be used instead of saying

PERFORM PROCESS-DATA-RECORD UNTIL FINISHED-IND = 'y' OR 'Y'.

This can be particularly useful if there is a whole range of possible conditions - as each may be given a name - e.g.

01 STUDENT-GRADE PIC 999.

$\begin{array}{ll}\text { 88 GRADE-IS-FAIL } & \text { VALUE 0 THRU } 49 . \\ \text { 88 GRADE-IS-PASS } & \text { VALUE 50 THRU 64. } \\ \text { 88 GRADE-IS-MERIT } & \text { VALUE 65 THRU } 84 . \\ \text { 88 GRADE-IS-DISTINCTION } & \text { VALUE 85 THRU } 100 .\end{array}$

These names may then be used in the Procedure Division -

e.g.

It is then possible to say:

IF GRADE-IS-FAIL THEN PERFORM FAIL-ROUTINE END-IF.

rather than:

IF STUDENT-GRADE < 50 THEN PERFORM FAIL-ROUTINE END-IF.

Note that the Data Definition entry is saying that there is one Data Item called STUDENT-GRADE which can take a number of different values - and these values can be referred to by a name so that the Procedure Division becomes easier to read.

\section{Exercise}

A data item called YEAR-OF-COURSE can take values from 1 to 3 . Complete suitable Data Division entries so that the following Procedure Division entry becomes valid:

IF FIRST-YEAR-STUDENT

THEN

PERFORM FIRST-YEAR-ENROLMENT-PROC

ELSE

IF SECOND-YEAR-STUDENT

THEN

PERFORM SECOND-YEAR-ENROLMENT-PROC

ELSE

PERFORM THIRD-YEAR-ENROLMENT-PROC

END-IF

END-IF . 